\title{
Fulfilling the Second Objective in the Online Catalog: Schemes for Organizing Author and Work Records into Usable Displays
}

\section{Allyson Carlyle}

An analysis of the requirements of the second objective of the catalog shows that it has two components, a retrieval component and a display component, and that it may be interpreted broadly to include related works and works about a work or author. Two schemes are investigated for their contributions to the creation of online catalog displays that meet second objective requirements. First, the catalog filing rule scheme is analyzed to show that author and work displays in card catalogs have been composed of many groups or classes of materials that may also be used to create organized displays in online catalogs. The groups used in the filing rule scheme are based on relationships among items. Second, a scheme based on Tillett's bibliographic relationship taxonomy is proposed to discover additional types of relationships that may be used to group records in online catalog displays. Finally, a new scheme for the creation of organized displays in online catalogs is proposed. It incorporates elements from both the filing rule scheme and the bibliographic relationship taxonomy to create displays that meet the requirements of the second objective more fully than either scheme does alone.

$\mathbf{T}$

he second objective of the catalog, adopted internationally in the Paris Principles, requires that records for particular authors and particular works be easily identified or ascertained (International Federation of Library Associations 1971). In practice, the second objective has been implemented by arranging together, or collocating, these records in catalog dis-

plays. Unfortunately, collocation is not easily obtained, particularly in online catalogs. The arrangements of records retrieved in figure 1 for a search on James Joyce's Ulysses and in figure 2 for a search on Charles Dickens exemplify the difficulty online catalogs have in fulfilling the second objective. Although records representing works by Dickens and editions of

Allyson CARLYLE (acarlyle@u.washington.edu) is Assistant Professor, Graduate School of Library and Information Science, University of Washington, Seattle, Washington. This paper is dedicated with great affection to those who have helped shape my views on the second objective: Betty Baughman, Seymour Lubetzky, Dee Andy Michel, Elaine Svenonius, Barbara B. Tillett, and Martha M. Yee. I would also like to thank Elaine Svenonius, Raya Fidel, Dee Andy Michel, Martha M. Yee, and the anonymous reviewers for helpful comments on earlier drafts of this paper, and Diane M. Thomas, who helped shepherd my study of filing rules. Manuscript received August 18, 1996; accepted for publication January 7, 1997. 
Ulysses are retrieved for each search in the same set of records, they are not arranged together, nor are they arranged in a useful or organized manner. Instead, they are scattered among records for other items, some of which are related and some not. Displays such as those shown in figures 1 and 2 obscure the presence of records for particular authors and works and, further, may confuse users, leading them to abandon searches under the mistaken assumption that the library does not own the work or works they seek.

This paper identifies schemes that might be used in the online catalog for organizing author and work records to achieve the second objective of the catalog. These schemes have in common the use of groups, or classes, based on relationships among items to organize catalog displays. The terms group and class will be used synonymously here. The use of relationship-based organization of records in catalog displays has the potential to increase a user's understanding of the nature of the items retrieved in an author or work search and to shorten long displays.

To begin, the second objective is reviewed in an effort to clarify its requirements. Next, the catalog filing rule scheme is investigated in a historical analysis to determine particular arrangements that have been used in catalogs to collocate work and author records. In this analysis, attention is paid to types of items frequently neglected in discussions of the second objective: works about a particular work or author, referred to in this paper as "works about," and works related to a particular work. Tillett's bibliographic relationship taxonomy (1991a) is then examined for its contribution to the construction of displays that meet the second objective. Following the investigation of these two schemes, a new, relationship-based

1. After Joyce: studies in fiction after Ulysses / Robert Martin Adams.

2. Blooms of Dublin / Anthony Burgess ... A musical play based on James Joyce's Ulysses.

3. The English in the West Indies, or, The bow of Ulysses / by James Anthony Froude.

4. Flower of the mountain : for soprano solo and orchestra (1986) / Stephen Albert ... text from Joyce's Ulysses.

5. A handlist to James Joyce's Ulysses : a complete alphabetical index to the critical reading text

6. James Joyce y la epica moderna : introduccion a la lectura de Ulysses / Manual Almagro Jimenez.

7. James Joyce's Ulysses / edited and with an introduction by Harold Bloom.

8. Joyce's notes and early drafts for Ulysses : selections from the Buffalo collection/ edited by Phillip F. Herring.

9. Narrative situations in the novel; Tom Jones, Moby-Dick, The ambassadors, Ulysses.

10. Odysseus / James Joyce [Swedish translation]

11. The personal memoirs of Julia Dent Grant (Mrs. Ulysses S. Grant)...

12. Songs to texts by James Joyce ... [includes song for Ulysses]

13. Ulysses / by James Joyce ; with a foreword by Morris L. Ernst ...

14. Ulysses. [by James Joyce]

15. Ulysses / James Joyce. [videorecording]

16. Ulysses : a review of three texts : proposals for alterations to the texts of 1922, 1961 and 1984 / Philip Gaskell and Clive Hart.

17. Ulysses, Kansas : 1:100 000-scale planimetric map ...

18. Ulysses pagefinder / compiled by Ian Gunn \& Alistair McCleery

19. Ulysses, soliloquies of Molly and Leopold Bloom [sound recording]

20. Ulysses. Spanish. 
scheme for author and work displays is proposed that combines features of the filing rule scheme and the bibliographic relationships taxonomy to show the nature of items retrieved and the relationships among them more clearly than either of the other two schemes alone.

\section{REQUIREMENTS OF THE SECOND OBJECTIVE}

As formulated in the Paris Principles, the requirements of a catalog stipulated by the second objective are somewhat vague: "The catalogue should be an efficient instrument for ascertaining ... (a) which works by a particular author and (b) which editions of a particular work are in the library" (International Federation of Library Associations 1971, xiii). What exactly is required of a catalog that it "be an efficient instrument for ascertaining" the works of an author and the editions of a work? Lubetzky, who greatly influenced this statement of the objectives, stated it more clearly: "The objectives which the catalog is to serve are two: ... to relate and display together [emphasis added] the editions which a library has of a given work and the works which it has of a given author" (Lubetzky 1960, ix). Lubetzky's wording clarifies the task of the catalog; for the catalog to "be an efficient instrument," it must relate and display together work and author records. His wording also makes apparent why the second objective is called the "collocating objective."

In the manual environment, the collocating objective involves filing work and author records together, one after another. Here an alphabetical arrangement of records provides for the retrieval and display of work and author records simultaneously. In the electronic environment,

1. Allen, Walter Emest, 1911-

Six great novelists: Defoe, Fielding, Scott, Dickens, Stevenson ...

2. Almar, George.

Oliver Twist. A serio-comic burletta, in three acts

3. Archaeology of urban America : the search for pattern and process / edited by Roy S. Dickens, Jr.

4. Carroll, John R.

A carol for Tiny Tim : the sequel to ... Dickens' "A Christmas carol"

5. Cronin, James Gerald, 1904-

Ground water in Dickens and Kent Counties, Texas ...

6. Dickens, Charles, 1812-1870.

Best thoughts of Charles Dickens arranged in alphabetical order...

7. Dickens, Charles, 1812-1870.

A Christmas carol.

8. Dickens, Charles, 1812-1870. Little Dorrit.

9. Dickens, Charles, 1812-1870. Oliver Twist.

10. Johnson, Charles Plumptre, 1853-1938.

Hints to collectors of original editions of the works of Charles Dickens

11. Korg, Jacob, ed.

12. Lewis, Bernard, 1908-

London in Dickens' day.

About "The Old Curiosity Shop"

13. Little Dorrit : film two: Little Dorrit's story / Sand Films [videorecording]

14. McKnight, Natalie.

Idiots, madmen, and other prisoners in Dickens

16. Structure and process in southeastern archaeology / edited by Roy S. Dickens

Figure 2. AUTHOR DISPLAY: Hypothetical Author Keyword Search on Dickens for works by Charles Dickens. 
however, the retrieval and display functions are separated. In an online catalog it is possible for all the editions of a work to be retrieved at the same time but not arranged together one after another or displayed together. Thus, the second objective may now be more accurately interpreted as having two requirements, a retrieval requirement and a display requirement. This paper focuses on the display requirement.

In the electronic environment, the word display can be used in a variety of ways. Discussions of online catalog displays have frequently focused on issues related to screen layout, consistency, highlighting, and other formatting issues (e.g., Online Catalog Screen Displays 1986). This paper emphasizes the organizational and intellectual aspects of display, specifically, the organization and arrangement of bibliographic records presented as a result of a search.

In formulating the requirements of the second objective precisely, another issue that must be addressed is stipulating what it is that must be collocated. The wording of the second objective does not specify what is to be treated as "the works of an author" or "the editions of a work." Is a single person or corporate body to be considered an author, regardless of the name that person or body uses in its works? Or does a different, albeit related, "author" exist when that person or corporate body uses a different name? In practice, the cataloging rules have sometimes called for creating different "authors" if they use different names and sometimes not. For example, differences in treatment of pseudonyms can be found between the Anglo-American Cataloguing Rules, 2nd ed. (AACR2) (1978; 22.2C2) and the Anglo-American Cataloguing Rules, 2 nd ed. 1988 revision (AACR2R) (rule 22.2B2). However, even when different authors have been created by the use of different names for the same person or body, practice has required the relating of the works of a single person or corporate body by the use of cross references. This practice may be interpreted as fulfilling the requirements of the second objective in that the works of an author are related, although all the works of that author have not, strictly speaking, been collocated.

For works, the picture is more complicated. More controversy has been aroused over what is to be considered to be an edition of a work than perhaps any other aspect of the second objective (for a summary of this controversy, see Yee 1994b, 1994c, 1995a, and 1995b). Seldom mentioned in discussions of this issue is that related items not considered to be editions are almost always filed together immediately following the editions of a work in an author display. Thus even related items that have not been treated as "editions of a work" per se have been included within the scope of the second objective by virtue of filing practice.

The inclusion of related works within the scope of the second objective is supported by cataloging theorists. Lubetzky, in his discussion of entry for works, includes the class of "dependent works," which he defines as those that are "written not for their own sake, but to accompany other works upon which they depend for their interest. Such are indexes, glossaries, supplements, appendices, cadenzas, librettos, etc." (Lubetzky 1953, 48). One assumes that he also had in mind a broad interpretation of the second objective when he made the assertion that: "[a cata$\log$ must call the reader's] attention to related [emphasis in text] materials in the library which might be pertinent to his interest and thus help him to utilize more fully and adequately the library's resources" (Lubetzky 1969, 10). Domanovszky's interpretation of the scope of the second objective with respect to works (Domanovszky 1975,98 ) is also broad:

the elemental objects to be brought together by the second function must be connected with one another by the identity of a nucleus of their contents; which necessarily implies that they must have in common, at least partly, also the intellectual source of their contents... The relationship constituted by the common intellectual nucleus of their respective contents may vary, for instance, between a complete identity of these contents and an absolute lack of any literal [emphasis in text] identity. 
Wilson (1989a) argues that although the concept of "work" should be defined narrowly, to include only those items that contain the same text, the scope of the second objective requires the catalog to assemble not only the editions of a particular work, but all the works related to that work. The term he applies to this assemblage is "literary unit," a term first used by Pettee (1936). Wilson states (1989a, 345):

... if we wanted to claim that the texts of items assembled by the second function should be nothing but texts of the same work, it would be awkward if the elemental objects we assemble as editions of Hamlet, for instance, include commentaries, introductions, prefaces, appendices by others, in other words, much text not plausibly identified as part of the text of Hamlet ... But for literary units this is no problem. They can comfortably be seen as assembling families of texts with related though not identical content and different miscellaneous attachments that may or may not constitute separate works by other authors.

This broader class of items consisting of sets of related works has also been called "superwork," a term first coined by Edward T. O'Neill and Elaine Svenonius.

Lubetzky includes a further class of items within the scope of the second objective: works about an author or work. In a paper written for the International Conference on Cataloguing Principles he identifies "entries under Bible where all the editions, translations, and works about [emphasis added] the Bible are found" (Lubetzky 1963, 142). It is probable that works about have seldom been mentioned in discussions of the second objective because these works are so obviously not editions per se. An interpretation of the second objective including works about within its scope is supported in cataloging filing practice, which in the last century has always required that records for works about a particular author or work file immediately following records for the authors and works themselves.

In summary, the second objective may be interpreted as requiring catalogs to retrieve as well as relate and display together (a) the works of an author-regardless of the name used by that author-and the works about that author and (b) the editions of a work, the works related to it, and works about it. In the following sections, two schemes, the filing rule scheme and the bibliographic relationship scheme, are investigated for their potential to help formulate displays that meet this objective.

\section{The Filing Rule Scheme}

The oldest scheme for meeting the second objective in display is found in catalog filing rules. Filing rules represent the most precise formulations of the second objective in that they spell out explicitly what is to be collocated in the catalog and how it is to be done. Analysis of these rules reveals the classes and subclasses of materials frequently identified for ordering work and author displays. For example, filing rules often include provisions for grouping items representing translations of a particular work and filing them after the group of items representing editions in the original language. Thus, filing rules extend the collocation requirement beyond the mere "displaying together" of work and author records to the displaying of these records in an organized and helpful manner. This is especially true for works existing in many editions and for prolific authors. In the sections on work and author filing below, the classes created by filing rules that comprise work and author displays are identified and reviewed.

In many respects, the manner in which records are arranged depends on their content. The content of records depends on cataloging practice, which is determined by the set of cataloging rules used at a given time. Because of this, any filing rules scheme must be regarded as drawing upon sets of cataloging rules as well as sets of filing rules. Although filing rules are the focus of the analysis that follows, cataloging practice is referred to when necessary to explain how specific classes are formed. Eight filing rule codes were analyzed:

- Panizzi's rules for the Catalogue of Printed Books in the British Museum, 1841

- Jewett's rules for the Smithsonian Re- 
port on the Construction of Catalogues of Libraries, 1853 (Jewett)

- Cutter's Rules for a Dictionary Cata$\log , 4$ th ed. rewritten, 1904 (Cutter)

- A.L.A. Rules for Filing Catalog Cards, 1942 (ALA 1942)

- Filing Rules for the Dictionary Catalogs of the Library of Congress, 1956 (LC 1956)

- A.L.A. Rules for Filing Catalog Cards, 2nd ed., 1968 (ALA 1968)

- ALA Filing Rules, 1980 (ALA 1980)

- Library of Congress Filing Rules, 1980 (LC 1980)

Each code is followed by the abbreviation that will be used in the analysis below. Although rules are often provided in these codes for subarrangement of records within each class or subclass, subarrangement rules are not addressed here. Further discussion on subarrangement issues may be found in Svenonius (1988), O'Neill and Vizine-Goetz (1989), and Ayres et al. (1995).

\section{WORK FILING}

Work displays created by codes of filing rules have, for the most part, been highly organized. Under the provisions of many codes, work records are arranged in classes and subclasses based on their relationship to the original publication of the work or their publication status; that is, whether they are published alone or with other works, or whether they are published in parts.

The class of records most frequently identified in the filing rules, and the class that almost always appears first in work displays, is editions of the work in the original language (Panizzi rule LXXV, Jewett rule XXXIV, Cutter rules 326-332, ALA 1942 rules 26(b) and 26(c), LC 1956, and ALA 1968 rule 27). The most recent codes of filing rules (ALA 1980 rule 2.2 and LC 1980 rule 6) do not make use of classes such as "editions in the original language" but rely instead on provisions of AACR2 and $A A C R 2 R$ for the use of uniform author names and uniform titles to collocate editions of a work in the original language automatically. Uniform titles, as constructed by $A A C R 2$, are purposely designed to provide elaborate groupings or classifications based on various characteristics of the items cataloged. Vellucci (1990) discusses the classificatory function of the uniform title in some depth.

Because the use of uniform title is optional (AACR2R, rule 25.1), editions of a work published under varying titles will not necessarily be displayed together. In actual practice, the use of uniform title is inconsistent and unless extraordinary efforts are made by individual libraries only some editions of a work in its original language will be displayed together, while others will be scattered alphabetically by their titles proper among records for completely different works (Carlyle 1996).

Provisions for analytics, that is, records for editions of works contained within collections, sometimes require that analytical records be interfiled with other edition records (Cutter rule 335, LC 1956 Aut. rule $\mathrm{IE}$ ). An example of an analytical record would be a record for an edition of Oliver Twist that is published as a volume in a set of Dickens' collected works. Filing analytics with records for editions published separately makes sense, since an edition published within a collection usually contains text identical to the text in an edition published separately. However, in some codes analytics are interfiled with unlike materials such as related works (ALA 1968 rules 26, 27) or are filed together as a separate class of material (ALA 1942 rule $25(7 \mathrm{~b}))$. One assumes that in codes that do not provide for analytics, the filing of these records is left to the discretion of the filer or the policy of the individual institution. In ALA 1980 and LC 1980 , analytics file as is; that is, the filing of these records depends on the presence and construction of analytical entries, which, in turn, allow for the interfiling of editions and related works in the same display.

A group of records representing translations of the original edition often follows the group of records for editions in the original language (Panizzi rule LXXV, Jewett rule XXXIV, Cutter rule 331, ALA 1942 rule $25(7 \mathrm{~b}), 26(\mathrm{~b})$ and $26(\mathrm{c})$, LC 1956 Aut. rule IG, ALA 1968 rule 27). Occasionally provisions are made for translations to be filed under their titles 
proper, treating them as if they were completely separate works unrelated to any other of the author's works (ALA 1942 rule 25, ALA 1968 rule 26). Using ALA 1980 or LC 1980 , translations would file after editions in the original language only if appropriately constructed uniform titles were used. If no uniform title were used, they would file as if they were separate and unrelated works.

In early codes, rules were created for special classes of materials closely related to the original work. Panizzi (rule LXXV) and Jewett (rule XXXIV) make arrangements for items containing the work both in the original language and in translation to be filed following editions in the original language. Many of the codes contain provisions for filing records for selections or portions of a work published separately (Panizzi rule LXXV; Jewett rule XXXIV; Cutter rule 326; ALA 1968 rule 27, footnote 37; and ALA 1980 and LC 1980 if appropriate uniform titles are used). ALA 1942 (rule 26(b)) specifies that records for manuscripts of a work file before records for editions in the original language.

Criticisms and other works about a work-called here works about-have also been grouped together as an integral part of the work display, following records more closely related to the original work. In Panizzi (rule LXXV), cross-references were filed at the beginning of a file, before any actual records were displayed. Although Panizzi rule LXXV does not explicitly mention works about, examples in this volume-see, for example, the listing under Aristotle's Logic on pp.330-332make it clear that references to works about file before editions of the work. Jewett (rule XXXVI) filed cross-references after all other pertinent records had been filed. In all other codes, including ALA 1980 and LC 1980, works about file together in a group following all the other records in a work display (Cutter rule 334, ALA 1942 rules 25, 26(a) and 26(b), LC 1956 Aut. rule III, ALA 1968 rules 26 and 27, ALA 1980 rule 2.2 and LC 1980 rule 6). ALA 1942 (rules 25 and 26(b)) and ALA 1968 (rule 27) make provisions for a criticism of a particular edition, translation, or part to file immediately after that particular edition, translation, or part.

Treatment of related works in the filing rules is somewhat difficult to discover. The related work category contains items that have many different relationships to the original edition. Examples of related works include sequels, supplements, indexes, concordances, screenplays, librettos, and subseries (AACR2R, rule 21.28A1.). Related works often have a main entry different from the main entry of the work to which they are related, but are given an added entry to show the relationship to the original. Related works have only within the last 50 years been identified and named as a particular class of materials in cataloging (American $\mathrm{Li}$ brary Association 1949). However, works of this type have, in practice, almost always been incorporated into work displays, often interfiled with works about. Some of the difficulties of ascertaining the treatment of related works in the codes are that they have either not been mentioned at all, they have been treated as equivalent to editions, or they have not been treated as a class of materials per se but referred to in the context of an added entry. For example, LC 1956 states: "If a book has some connection with another author's work, but is not a criticism of it and does not include the original text, an added entry is often made under that author. In that case the title of the work in question is included as part of the added entry heading. As an added entry the card is filed after the texts of the work and before the criticism (or subject) cards for that work" (LC 1956, 19).

In ALA 1968, related work added entries are formally identified as "author-title added entries" and provisions for filing them state that they are to interfile with analytic entries, which have the same form, and follow edition records and precede records for works about (rule 26(b) and 27). Again, this creates a class composed of two very different types of materials, analytical editions and related works. In ALA 1980 and LC 1980, author-title added entries, now called name-title added entries, are treated as equivalent to main entries (rules 2 and 6, respectively). Thus, in catalogs following these rules, 
work displays are even more confusing because related work records interfile among edition records and analytical edition records.

Special treatment is accorded works represented by very large numbers of records in several of the codes, providing for even more classes of materials, thus creating even more highly organized displays. Panizzi (rule LXXIX), and Jewett following him (rule XXXVII), specify rules solely for arranging records for the Bible. By the time ALA 1942 was published, special rules were included for "anonymous classics" as well as the Bible (rules 28-30). LC 1956 (anonymous classics rule) and ALA 1968 (rules 29-30) also contained special provisions for filing anonymous classics and the Bible. Again, ALA 1980 and LC 1980 provide for organized arrangements for all works only insofar as the correct uniform title headings are used in individual records.

\section{AUThor Filung}

Author displays, like work displays, have usually been composed of various classes of author records. All filing codes provide for grouping works by an author together. However, prior to 1968, the major codes divided the works of an author into various subclasses, particularly for classic or voluminous authors. In Panizzi (rule LXX), Jewett (rule XXXIV), Cutter (rule 326), ALA 1942 (rules 26(a), 26(b), and 26(c) for classic and voluminous authors), and LC 1956 (Aut. rule IA), the first class of works by an author consists of complete works of an author. Some of the codes further subdivide this class into complete works in the original language, complete works in the original language and in translation, and complete works in translation only (Panizzi rules LXX-LXXII, Jewett rule XXXIV), although rule 26(a) in ALA 1942 stipulates two categories only: complete works in the original language and complete works in translation.

Following complete works is a class containing selected works of an author (Panizzi rule LXXIII; Jewett rule XXXIV; Cutter rule 326; ALA 1942 rules 26(a), 26(b), and 26(c)). LC 1956 (Aut. rule I) combines complete and selected works into a single class. As with complete works, selected works might be subarranged into various groups based on language of text. Catalogs following ALA 1968 (rule 27 for organized author arrangement), ALA 1980, or LC 1980 would create author displays that grouped complete works and selected works only if uniform titles were used. Uniform titles create groups containing complete works as well as groups containing specific types of works, for example, plays, essays, poems, etc. by use of collective uniform titles, for example, "Works" or "Essays" (Anglo-American Cataloguing Rules (1967) rule 107; AACR2R rules 25.8 and 25.10). Actual catalog displays from early catalogs also reveal classes containing specific types of works in displays for various prolific authors. For example, the Shakespeare display in the Catalogue of the Library of the Boston Athenæum features the special classes "Separate Plays" and "Poems" which file after "Selections" (Boston Athenæum 1874-1880, 2707-2708).

In ALA 1942, selected works are combined with selections from a single work or from various works (rule 26(a)). In other codes, selections from a single work or various works are grouped together separately and filed either before single works of the author (Panizzi rule LXXIV, Jewett rule XXXIV) or after (ALA 1942 rule $26(\mathrm{~b})$ and $26(\mathrm{c}))$. Again, the filing of selections from a single work or from various works in ALA 1968, ALA 1980, and LC 1980 depends on whether or not uniform titles containing the collective title "Selections" were used in the record.

Single works by an author are treated as discussed in the section on work filing above. However, an early practice not mentioned above distinguished works by an author as main entry and the author as joint author, illustrator, editor, etc. (see discussion in Cutter 1904, 119). LC 1956 required the interfiling of author as main entry and author as joint entry, but created a separate group for the author as compiler, joint compiler, editor, etc. (Aut. rule IIA). Some online catalogs containing cataloging records with relator designations following the author name in the author heading, for example, "ed.," create 
separate groups for these records because filing programs sort on relator terms. Relator terms are seldom used today; thus such groups might be misleading to cata$\log$ users because they give the impression that all the works edited, etc., by an author might be found in such groups.

Sometimes displayed as a separate group are spurious and doubtful works. ALA 1942 explicitly mentions these works, requiring that they file after the known works of the author (rule 26(b)). Because the A.L.A. Cataloging Rules for Author and Title Entries (American Library Association 1949) and previous sets of cataloging rules stipulate use of a form subdivision "spurious and doubtful works" in an author heading for works of this nature, those catalogs constructed by such rules would group these works automatically by following the rules for alphabetical filing. Panizzi's last author grouping contains "works not written by the person but under whose name they will be cataloged" (rule LXXVII), which would perhaps have contained spurious and doubtful works if they existed.

The last class of materials common to all the codes is works about the author, including both biographies and criticisms. Works about usually file last in an author display (Cutter rule 326, ALA 1942 rules 25,26 (a) and 26 (b), LC 1956 Aut. rule III, ALA 1968 rules 26 and 27, ALA 1980 rule 1980 and LC 1980 rule 6). In actual catalogs, works about can outnumber the actual works of an author, particularly works about classic and voluminous authors, and may thus comprise a significant portion of an author display.

An unusual arrangement is stipulated in ALA 1942 rule 26(c), one of the optional rules for arrangement of classic and voluminous authors. It requires that texts of all types by the author in the original language be filed in one group, followed by groups of texts in various translations filed by language. Each of these two major groups is subdivided into the following classes: complete works, selected works, single works, spurious and doubtful works, and selections. These two major groups are followed by three categories of works about: biography and general criti- cism, criticism of single works, and other subject entries for the author.

In later codes, rules for the creation of author displays are quite simple, specifying two classes only: works by the author and works about the author (ALA 1942 rule 25, ALA 1968 rule 26, ALA 1980 rule 2.2 , and LC 1980 rule 6). These displays separate groups of work records from works about the work (criticisms, for example). In addition, as mentioned above, if uniform titles are not used, such displays do not collocate the editions of a work because they separate records for editions that have varying titles proper or translated titles and they interfile records for related works among edition records. In ALA 1942 and ALA 1968, the simple by/about display was recommended for nonclassic or nonvoluminous authors only, presumably because these displays would consist of few records.

Finally, cross-reference records are often used in author displays. See references are used to refer users from various forms of an author's name. See also references are used to refer users from various names used by the same author. In a listing of titles under author name, see references can be made from variant titles of an author's work to its uniform title (e.g., AACR2R rule 26.4; illustrated in fig. 3 on lines 3 and 7). This type of see reference was used in early catalogs when no records were filed under variant titles and all records were filed under uniform titles. Such see references are still sometimes used to direct users to uniform titles. However, few online catalogs are able to display title references and, mimicking the card environment, display them under author name only and not under title as well. Furthermore, few catalogs, if any, follow early catalog practice and display the see reference instead of records under the variant title.

Those online catalogs displaying title see references frequently display records containing the same variant title in proximity to the title reference, sending a potentially confusing message to the users (see lines $3,4,6,7$, and 8 in fig. 3). In addition, the title that they see on the screen usually represents records for related 
works (see line 6 in fig. 3); records for editions of the work they are actually seeking are buried in the group of records that appears under the author name alone (see line 2 in fig. 3). See and see also references can also be used to direct users to parts of works cataloged independently (for example, AACR2R rule 26.4B2) and to direct users from related work entries to the work to which they are related (for example, AACR2R rule $26.4 \mathrm{C}$ ), respectively.

\section{Filing Rules Discussion}

All of the codes of filing rules, including ALA 1980 and LC 1980, require the formation of groups of work and author records based on their relationships to each other. Groups are defined because the items in them share specific relationships to each other. For example, in the translations group, all items share the same relationship to the original in that they have all been translated into a language different from the language of the original. The extent to which grouping based on specific relationships has occurred in the display of works and authors has frequently depended on the number of records associated with them. In the words of ALA 1968 (113):

Arrangement of all works by title page title is suitable only for a small collection with relatively few titles under an author. An organized arrangement should be introduced in situations where the alphabetic order becomes difficult to consult because of the number and character of the titles, editions, translations, etc., as under classic and voluminous authors...

Large files have always presented a problem for catalog users, and grouped arrangements have been used as means of solving this problem. However, if the groups used in ordering are not clearly marked, the resultant arrangements may be confusing to users, which was noted by Jackson in his study of catalog use (1958). The dangers of grouped arrangements in the card environment were identified early on. Cutter, with his usual perspicuity, noted (rule 326):

... practice hitherto has been to arrange entries by joint authors after the works written by the first author alone... but although it is pleasing to a classifying mind, it is practically objectionable because a reader, not knowing that the book he is looking for is a joint production, and not finding it in the first series of titles, might suppose that it is not in the library. This danger is greatest in a card catalog, where it entirely overweighs the somewhat visionary advantage of the separate arrangement. The arrangement of a card catalog should be as simple as possible, because the reader having only one card at a time under his eye can not easily see what the arrangement is. On the printed page, where he takes in many titles at a glance, more classification can be ventured upon; there the danger is confined to the more voluminous authors; where there are few titles the consulter will read them all and so will not miss any.

Search on: DICKENS CHARLES

\section{Line Entries Author/Title}

11 Dickens, Charles, 1719-1793.

2283 Dickens, Charles, 1812-1870.

30 Dickens, Charles, 1812-1870. Annotated Christmas carol.

$411 \quad$ search for Dickens, Charles, 1812-1870. Christmas carol.

53 Dickens, Charles, 1812-1870. Bleak House.

611 Dickens, Charles, 1812-1870. Christmas carol.

70 Dickens, Charles, 1812-1870. Christmas carol in prose.

811 search for Dickens, Charles, 1812-1870. Christmas carol.

91 Dickens, Charles, 1812-1870. Christmas carol. Selections.

101 Dickens, Charles, 1812-1870. Christmas carol. Selections. 1992.

Figure 3. Work Cross-Reference Display Under Author Name. 
One solution to the problem of users being unaware of grouped arrangements was to insert guide cards to mark the beginning of record groupings. However, it was never widely implemented. Thus individually alphabetized groups of records were filed in card catalog work and author displays, and there was seldom any indication of when these classes began or ended or what they represented.

Librarians frequently criticized these highly organized, classified arrangements, for the reasons identified by Cutter (for example, Scheerer 1959). In addition, when early online catalogs were developed, it was discovered that contemporary codes of filing rules (LC 1956 and ALA 1968) relied heavily on human interpretation and contained many exceptions, attributes with which computers were unable to cope (Wellisch 1983). The argument was made that "filing should be a purely mechanical operation which can be reduced to a straightforward arrangement of sorts and nulls. The filer or program should not be expected to expand or interpret for filing purposes" (Hines 1963, 8-9). Those advancing this argument prevailed, and ALA 1980 and LC 1980 were developed to accommodate the inflexibility of the computer by simplifying the filing process (ALA 1980, 1-3; LC 1980, 2-3; Anderson 1982).

As mentioned earlier, ALA 1980 and LC 1980 reduced the number of classes of records in work and author displays to two: editions or works, including related works, which are interfiled, and works about. However, whether or not these classes were formed depended almost entirely on the presence of uniform author and title headings. In any case, the reduction in the number of classes has not eliminated the "large file" problem, which continues to haunt catalog users (see, for example, Wiberley, Daugherty, and Danowski 1995). The online catalog's inability to demonstrate relationships among records has been suggested as contributing to the large file problem (Carlyle 1996). This inability stems in part from the abandonment, by codes of filing rules, of classified displays in which relationships among items can be shown. Abandoning this method of showing relationships is even more serious considering that current research advocates an even more detailed organization of relationships among items in the cata$\log$ (for example, Svenonius 1988, Tillett 1991a, Smiraglia 1992, Leazer and Smiraglia 1996).

\section{The Bibliographic RELATIONSHIPS SGHEME}

A second scheme that may be used to guide the creation of displays that meet the second objective for works is based on Tillett's taxonomy of bibliographic relationships (1991a), which was developed to facilitate the creation of a conceptual model of the catalog. Tillett, in her relationship taxonomy, spells out the types of relationships that exist among works. Although the taxonomy was not necessarily intended as a scheme for creating online catalog displays of works, it does define relationships that might be used to group items related to works in the catalog. The groupings that are suggested by Tillett's bibliographic relationships are first reviewed and then compared to the traditional groups created by filing and cataloging rules (see Tillett $1991 \mathrm{~b}$ for a complete review of the treatment of bibliographic relationships in cataloging rules).

Tillett defines the equivalence relationship first. Equivalent items share intellectual and artistic content as well as authorship, and her examples include copies, facsimiles, and photocopies. A grouping of records based on the equivalence relationship can be regarded as a subset of the filing group "editions of the work in the original language." However, the original-language editions group also includes editions that have the same content and authorship but might vary in other respects; for example, they might have different publishers, editors, or illustrators. In addition, the original editions filing group might contain items that do not share identical intellectual and artistic content, for example, revisions and abridgments.

Next, the derivative relationship exists between any item and another item that has been derived from it. The range of items sharing the derivative relationship extends from items that exhibit only small differences in intellectual and artistic content to 
those that have very little intellectual and artistic content in common. For example, it may hold between editions that are nearly identical, as between an original edition and a corrected edition published by the same publisher and, at the other extreme, between a textual edition of $A$ Christmas Carol and a French pop-up book version, a video or audio performance, or $A$ Christmas Carol card game.

Smiraglia $(1992,28)$ refines derivative relationships into various subrelationships. Smiraglia's seven derivative subrelationships include: simultaneous derivations, successive derivations, translations, amplifications, extractions, adaptations, and performances. Some of his subrelationships have been slightly modified or renamed in the following discussion to facilitate comparison to filing rules groupings. Because the number of items that can fall into the derivative relationship category is so large, Smiraglia's subrelationships have the potential to be especially useful for grouping items in display.

Revisions, which Smiraglia calls "successive derivations," consist of items that have been revised. Another way of looking at revisions is to say that they have been changed in such a way as to alter the intellectual and artistic content of the original without changing its intellectual and artistic intent, form, or format. In this paper, a distinction is drawn between content, on the one hand, and intent, form, and format, on the other, because it is seen as being central to making distinctions between different types of derivations. Intellectual and artistic intent might include intended audience, purpose, point of view, or discipline represented by a work. Form includes internal structure; for example, textual forms include outlines, prose, plays, poetry, etc. Format includes external or physical structure, for example, sound recordings, videorecordings, books, etc. It must be noted that some changes in format do not indicate a derivation, in particular, those that replicate the conditions under which the original item is experienced (Helmer 1987). For instance, editions appearing on audiocassettes and compact discs, or editions appearing in book format and microform, could be considered to be equivalent. With this exception noted, a revision may thus be defined as resulting from a change in intellectual or artistic content without alterations in the intent, form, or format of the original.

Revisions have been included in two different groups in filing practice depending on authorship conditions and titles used. If authorship conditions and title of the original edition have been preserved, then revisions have normally been grouped with the original editions, although treatment in this area has varied in cataloging history. In $A A C R 2 R$, if authorship conditions or title have changed, then revisions have been treated as new works. Name-title added entries are not created for all revisions treated as new works, and thus records for these revisions have not been filed with records for the original consistently.

Revisions can be contrasted to adaptations, which alter the intellectual and artistic intent, form, or format of an original edition as well as its content. Smiraglia's examples include simplifications, which may result from the desire to present the work to a different audience, and screenplays adapted from prose works, which change the internal structure of a work and may, in addition, include various changes of intent. Other changes in artistic intent, form, and format include parodies, dramatizations, free translations, and reproductions of artworks. Yee (1994c, 1995a) identifies many types of items that would be included here in parts 2 and 3 of her review of the concept of "work." We might also wish to add here another of Smiraglia's derivative subrelationships, performance, sound or video, as a type of adaptation.

Most adaptations, including performances, have been treated as new works in traditional cataloging practice because they involve a change in authorship conditions. A notable exception is music; performances of musical works have been treated as editions of the original work. In practice, treatment of adaptations is similar to that of revisions involving a change in authorship conditions; name-title added entries may or may not be required, and thus records for adaptations and performances may or may not be grouped with records for the original. 
Smiraglia also identifies translations and extractions as separate types of derivations. Translations have always been identified in catalog displays and, as a group, are identical to the group identified in traditional practice. Smiraglia does not address the display issue, but subgrouping by language for display purposes, consonant with filing rule practice, is a logical extension of the translation grouping.

Extractions include abridgments, condensations, and excerpts. Smiraglia includes excerpts in the extractions subrelationship. Excerpts might also be considered to bear a type of whole-part relationship to an original. The whole-part relationship is discussed below. Extractions have often been treated as editions, or as equivalents, in traditional cataloging practice (Yee 1994c), with the exception of abridgments that are seen as the work of the abridger, which are treated as new works related to the original and given name-title added entries. As a result, records for extractions have often been interfiled with records for original editions in traditional filing practice.

Amplifications of a work occur when a new work has been created or produced to amplify, add to, or extend the original in some respect (Smiraglia 1992). One may or may not wish to regard amplifications as a type of derivation. A case might be made for amplifications to be on a parallel footing with Tillett's other bibliographic relationships. Also, amplifications subsume a large part of Tillett's accompanying relationship, which, in this paper, is not being regarded as a separate bibliographic relationship (see discussion below). The new work may or may not be published with the original. Examples that Smiraglia gives include illustrated texts, musical settings, and concordances. In traditional cataloging practice, amplifications published with the original have most often been grouped with records for the original work as if they were identical to them. Amplifications published separately are usually treated as different works and related with a name-title added entry. Records for these items are then frequently interfiled with records for the original work.
The whole-part relationship holds "between a component part of a bibliographic item or work and its whole" (Tillett 1991a, 156). Current cataloging practice calls for the identification of parts or selections using either a uniform title (AACR2R, rule 25.6 ) or a note identifying the host item. If a uniform title is not used, records for parts can be arranged randomly among records for the whole item; in some instances they can interfile among totally irrelevant records. If a uniform title is used, separate groupings are created for each part because the part name is included as an extension of the uniform title.

A whole work that is published as part of a collection can be identified with a name-title added entry and, in most filing codes, interfiled with other records for the work, but the practice of assigning nametitle added entries is limited to collections comprised of three or fewer separate items (AACR2R, rule 21.7B1). Sometimes separate works are identified in contents notes only, and frequently they are not identified at all. As a result, bibliographic records display the whole-part relationship inconsistently.

The sequential relationship holds between an item and other items following or preceding it. This relationship also has been treated in a variety of ways in cataloging practice. For serial title changes, practice has varied from creating a single record with added title entries for the various titles used, to creating a succession of entries representing the various titles used with linking added entries. Recently successive entry has been used. Use of successive entry for serials implies that serials whose titles have changed are different works. However, added entries for an earlier and a later title are mandated, thereby partially grouping records under both old and new titles in the catalog and treating them as related works.

Items exemplifying other types of sequential relationships-in particular, fiction sequels - are rarely identified in cataloging practice. If fiction sequels are identified, identification is usually limited to a note and not an added entry. In this way the two schemes differ in the groupings that would be created in a work dis- 
play; the traditional filing rules scheme would place far fewer items in this category than the bibliographic relationships scheme.

The descriptive relationship translates more or less into the class that has been referred to here as works about a particular work. Works in this relationship are exemplified by criticisms, commentaries, and reviews. Cataloging practice prescribes that subject added entries be included in records for items bearing this relationship, and filing practice has called for this group of items to be filed together at the end of a file of work records.

The shared characteristic relationship is found among any two items that share an identical characteristic, such as an author or work name. In filing practice, records are grouped when they share identical access points, and thus groupings created by this relationship would be identical to those created by filing rules so long as the shared characteristic has been given an access point. Groupings would not be made in a catalog for characteristics not given access points, although an online catalog that has keyword searching of all fields makes such groupings possible if the characteristics appear in the bibliographic records.

Tillett describes the accompanying relationship as holding between two or more items that are published together or are meant to be used together-between an item and another item accompanying it. I would argue that there is no need for a separate category for accompanying relationships, because although accompanying materials are related, they always share one or more of the relationships described above.

All of the examples that Tillett gives of items of the accompanying relationship can be placed into one of the bibliographic relationship categories described above. Her examples include a predominant item and a lesser item, e.g., a text and its supplements. A supplement to a text might be regarded either as an amplification or a sequel, depending on the nature of the supplement. Other predominant items accompanied by lesser items, such as a geography text accompanied by an atlas, a children's book accompanied by a doll, or a computer file accompanied by a manual, could all be seen as amplifications. Items that provide access to other items, Lubetzky's "dependent works" category, including concordances, indexes, and catalogs, might also be regarded as a special type of amplification. Tillett's last example, the separate components of a kit, do not necessarily represent a bibliographic relationship in that they, like chapters in a book, comprise the item. If the individual components of a kit are separated for some reason, then the whole-part relationship might be appropriately applied to describe the relationship of the part to the whole and vice versa.

\section{Problems in the Creation of ORGANIZED AUTHOR AND WORK DISPLAYS}

Each of the schemes discussed above, the filing rules scheme and the bibliographic relationships scheme, falls somewhat short of creating displays that fulfill the second objective because they do not identify clearly the nature of, and relationships among, items retrieved in a search for an author or work. In this section, the filing rules scheme and the bibliographic relationships scheme are evaluated with respect to their limitations in guiding the creation of catalog displays. The effect of keyword searching on the creation of relationshipbased displays is analyzed as well.

\section{Evaluation of the Filing Rules SCHEME}

One critical weakness of the filing rules scheme is that it depends on record content for grouping. This is unsatisfactory for two reasons. First, record content is determined by cataloging rules, and sometimes the cataloging rules do not require the necessary content. For example, because AACR2R and earlier codes have not required the use of uniform title, many records that are related cannot be grouped together in catalog displays because they lack a uniform title. Even items that share identical intellectual and artistic content might be treated as different 
works because uniform titles are not used. Another example is parodies; AACR2R does not require a name-title added entry for the work parodied, and as a result, the relationship between a parody and the work parodied is not shown.

A second reason that dependence on record content for grouping is unsatisfactory is that online catalogs might misfile or ignore catalog headings in filing. When catalog headings that are intended to group records together are misfiled or ignored, the records representing particular works and authors are scattered. For example, name-title added entries are frequently filed not as two separate headings, a name and a title, but as a single heading (see line 6, fig. 3). Another example is filing the works of an author under titles proper instead of uniform titles. Although these problems might be remedied by corrected programming, thus far many online catalog designers do not seem to be inclined to move in this direction.

Another weakness of the filing rules scheme, particularly when viewed in the context of works and the bibliographic relationships scheme, is that it does not sufficiently distinguish among items that bear different relationships to each other, treating as equivalent items that are, in fact, quite different. As Wilson has pointed out on numerous occasions (e.g., 1983), the traditional filing rules scheme does not identify items that contain identical texts. Even when editions are grouped together, it is up to the user to look carefully at each bibliographic record to determine which one, for example, represents the most recent edition. The greatest failure to make distinctions among different types of items is in the group of items that are assigned name-title added entries. These items might bear equivalent, derivative, or sequential relationships to a work. Currently only one distinction can be made among these items. The name-title added entry provided by the MARC format allows two groups to be distinguished: a group of related works, which includes items bearing derivative and sequential relationships, and a group of analytics, which includes items bearing an equivalence relationship.

\section{Evaluation of the Bibliographic RELATIONSHIP SCHEME}

One of the major weaknesses of the bibliographic relationship scheme is that the intellectual and artistic distance of items bearing a bibliographic relationship to an original edition is not taken into account, nor are authorship conditions. Intellectual and artistic distance can be viewed in part as changes in a work that involve its intent, form, or format, as discussed above. Authorship conditions, particularly primary authorship, inherent in main entry decisions, are closely related to such changes in that a change in main entry indicates that an item has moved a significant distance away from the original.

Traditional cataloging practice has generally divided the derivative relationship into two groups based on authorship conditions represented in the items. This division might be seen as an indication of the distance of a particular derived item from the original. In the first group are those items whose authorship is represented as being the same or nearly the same as the authorship for original item, for example, an edition updated or revised by the original author(s). Changes in subsidiary authorship-for instance, changes in illustrators or the addition of translators-have not been considered to change significantly the authorship conditions of the original edition.

In the second group are those items whose authorship is represented as being different from the original, for example, an adaptation for children by a new author, an edition completely revised by another author, or an adaptation into another format. While we might wish to make more distinctions than these two, it would be just as unwise to group all items sharing the derivative relationship together without making distinctions based on distance from original or authorship conditions. The subgroupings of the derivative relationship suggested by Smiraglia remedy much of this problem, but even so, it may be misleading to users if all of these subgroupings appeared together in a work display as a single class.

Several aspects of the bibliographic relationship scheme could be modified to 
make it show the nature of items in a work display more clearly. The equivalence relationship as set forth by Tillett does not distinguish between items sharing identical text or intellectual content only and items sharing identical or nearly identical title page representation as well as identical content. For example, it does not distinguish the relationship between an item and a photocopy of that item (items that share identical or nearly identical title page representation, paging, and content) and the relationship between an item published by one publisher and an item with identical content published by another publisher (items that share identical content only). Tillett's list of examples suggests that she understands the equivalence relationship to hold between items sharing identical title page representation, paging, and intellectual content. Yee (1994a) has recommended that these items be considered near equivalents and be described by the same bibliographic record, with an indication of changes in format or other minor changes. With respect to items sharing identical intellectual content only, Wilson (1989b) has argued that our conception of "work" should include only these items, which he calls texts. It makes sense to refine Tillett's equivalence relationship in display along these lines by incorporating near equivalents into the display of a single bibliographic record, as recommended by Yee, and by grouping items that share identical intellectual content, regardless of title page representation, as suggested by Wilson.

Smiraglia identifies a type of relationship-the "simultaneous derivation"that might be helpful to treat as a subtype of equivalence relationship (Smiraglia $1992,28)$. This relationship is called here an orthographic modification. Editions of an English work published in the United States might include differences in spelling, and a textual work might be published in large print or Braille. Changes such as these do not affect the intellectual or artistic content of a work. Orthographic modifications have never been classed separately in any set of filing rules, but have been treated as equivalent editions. When a work has many orthographic modifications, this relationship might be an important means of helping users identify quickly the items they need.

It might also be useful, depending on the work displayed, to analyze some of Tillett's bibliographic relationships into subrelationships, much the way Smiraglia has done with the derivative relationship. For example, items sharing whole-part relationships could be divided into a group of items in which the whole appears with other items in a collection and then into another group of items that contains parts only. Another example is the sequential relationship; items sharing the sequential relationship could be grouped according to whether they appear earlier in a sequence or later than the work displayed. Bernhardt (1988) suggests this type of display for serials that have undergone title changes. The problem of displaying sequels and serials is analogous to the problem of relating records for corporate authors or other authors represented under two or more different and sequential names. Bernhardt's proposal for alternative serial displays provides a blueprint for clarifying displays of sequentially related author names in the catalog as well.

\section{KEYWORD SEARCHING AND DISPLAY}

Any implementation of the second objective is challenged in the online environment by a phenomenon that could not have existed in the manual environment, which is the retrieval of records for items that are related to a particular work or author but that have not been explicitly linked in cataloging practice to that work or author. Although these items lack deliberate cataloging links to the related work or author, they are retrieved in keyword searches (that are assumed to have Boolean functionality) because relevant uncontrolled names or titles are embedded within access fields or are present in nonaccess fields (see items 1, 9, and 12 in fig. 1 and 1 and 11 in fig. 2). Items in this group are of two types. First are items that, for a variety of reasons supported by cataloging rules, lack deliberate links but are, in fact, editions, related works, or works about the work or author sought (unlinked works or authors). Second are items that lack de- 
liberate links to a particular work or author because they bear only a peripheral relationship to that work or author (peripherally related works). Peripherally related works include those that devote a small percentage of content to a particular author or work or those that mention a particular author or work in passing. In keyword searches for prolific authors and highly manifested works, many records of both types might be retrieved.

In principle, all records for particular authors and works should be grouped according to the second objective. However, for various reasons, cataloging rules and practice have not required the creation of explicit links in every record for items that incorporate the work of an author or an edition of a work. For example, if an edition of a work is published in a collection of four or more works (AACR2R rule 21.7) or if a translator or illustrator does not fulfill basic added entry requirements (AACR2R rule $21.30 \mathrm{~K}$ ), explicit linking is not required. The reasons for this are primarily economic; the price of explicit links is high and as a result, the number of links has been limited.

Fortunately, some unlinked records can be identified automatically. For example, many editions of works are contained in single-volume collections of an author's works. In many records for these collections, the author's name appears in the main entry field and titles of the contained works appear in the contents note field. In these cases, records for single-volume collections containing editions of single works could be automatically identified and grouped with other equivalent items. Unfortunately, not all unlinked records are so easily identified. However, many of those that are not could be grouped with peripherally related items and thus become somewhat accessible to catalog users.

Any argument to include peripherally related items in the second objective with other items more closely related to a particular work or author can be challenged. Nonetheless, it is the case that these items are retrieved and displayed in keyword searches, that catalog users see them in the set of retrieved records, and that their relationship to the work or author sought, however slight, will be recognized. To in- clude these items formally within the scope of the second objective would require a change in current practice such that catalogers would be required to assign explicit links to all items bearing any relationship, no matter how slight, to an author or work. Such a move is undoubtedly impossible given economic constraints. Further, and perhaps more important, it may not be desirable to water down the groups of closely related items with items that are more distantly related to a work or author sought. On the other hand, to group these items with totally unrelated items might also be undesirable given that they will be seen and might be of interest to some catalog users.

A compromise position would take advantage of existing computer technology and would group peripherally related items at the end of an author or work display automatically. For example, once all the records containing explicit links for Joyce's Ulysses were organized, the remaining records could be searched using the terms "ulysses" and "joyce." Those records that contained both terms could then be grouped into the peripherally related records category. Because this grouping would rely on the existence of uncontrolled author names and titles, it would not be perfect, nor would all peripherally related records be assembled. However, labels identifying classes of peripherally related and unrelated records in a catalog display could indicate the uncertainty of the classification. A message such as "Items probably related to [name of work or author]" could identify those items automatically identified as peripherally related, while the group of unrelated records could be accompanied by the message "Items that may or may not be related to [name of work or author]."

\section{The Organized Display Scheme: \\ A New SCHEME FOR FULFILLING THE SECOND ObJEGTIVE IN THE Online Catalog}

The preceding review and analysis of the filing rule and bibliographic relationship schemes lay the groundwork for the development of a scheme that fulfills the sec- 
ond objective to a greater extent than has been accomplished before. This new scheme, the organized display scheme, combines the strengths of both of the earlier schemes to give users a precise indication of the nature of items retrieved and the relationships among them by taking into account both the types of relationship present among items as well as the distance of an item from the original. It also acknowledges the presence of peripheral and unlinked items retrieved in a keyword environment.

The emphasis in this paper has been on the identification of groups or classes of items that share specific relationships. The reason for this was to facilitate the creation of summary displays in which all the records for a particular work or a particular author could be displayed on a single screen. Evidence exists that some catalog users, when confronted with large sets of retrieved items, leave the catalog without consulting a single record (Wiberley, Daugherty, and Danowski 1995). The compression of large retrieval sets of work and author records onto single screens has the potential to relieve this problem of overload.

WORK NAME / AUTHOR NAME

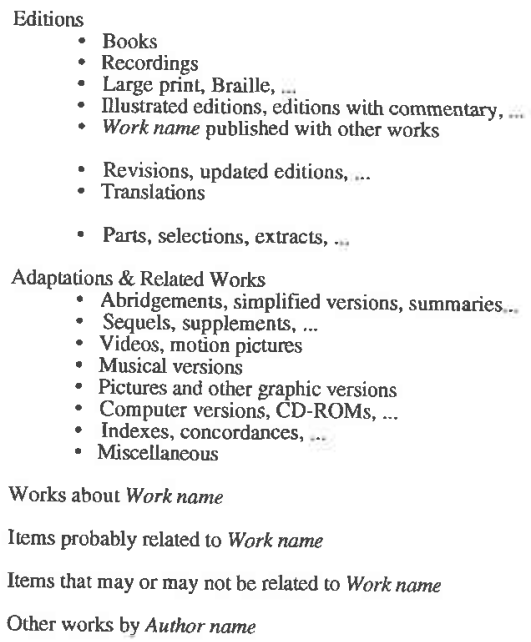

Figure 4. Summary Work Display for Text Original.
In figures 4 and 5 , summary work and author displays are suggested. These summaries are suggestions only, because different works are manifested in different ways and would be served best by customized displays. For example, some works have been adapted many times and have many related works associated with them and some do not. If few adapted and related works are associated with a particular work, then that grouping could appear as a single selection under "Editions" and not as a major grouping with specified subgroupings. Likewise, if many items in a subgrouping existed, for example, amplifications of a particular work, it would be useful to divide that group into subgroups, perhaps grouping all of the texts that have been illustrated and then all of the texts that have been published with commentaries, and so forth. Another reason that the work display in figure 4 is only a suggestion is that it assumes that the original edition is a text; originals that are not texts would require slightly different summary displays.

In the summary work display (figure 4), those items whose intellectual and artistic content are close or identical to the original work -in other words, the items that are normally given the same main entry-appear together in the first major grouping of items on the screen. Items sharing the same text appear in the first

\author{
Single Works \\ Work names $A$ - $H$ \\ Work names $I$ - $O$ \\ Work names $P-Z$ \\ Collected Works \\ Selections from Author name's works \\ Spurious and doubtful works \\ Works about Author name (biography, criticism, ...) \\ Items probably related to Author name \\ Items that may or may not be related to Author name
}

Works by the same/related author: Author name 2

Figure 5. Summary Author Display. 
five subgroups, with revisions and translations appearing next, and finally items that represent parts only. In the next major grouping are those items whose intellectual and artistic content are further from the original by virtue of the fact that their intellectual or artistic intent, form, and format have been altered. These items have normally been given main entries different from the original. The subgroupings in this category include videorecordings and musical and computer versions. A miscellaneous category is included for items that might not fit any of the other adaptations and related works subgroupings exactly.

The summary author display (figure 5) is based entirely on the filing rule scheme, since the bibliographic relationship scheme applies to works only. Like work displays, displays for individual authors could be customized according to the relationships among the items retrieved. Few authors, for example, would have any items appearing in a "spurious and doubtful work" category, and it would seldom be needed in an author display.

One of the limitations of summary displays such as the ones suggested here is that relationships between individual items that are different from their relationship to the original are hidden. For example, a work about another work might be about a particular part of it only, or a translation might have been made of a particular revised edition. In a sophisticated online catalog using individual item linking, such as hypertexttype linking, items that share relationships to each other might be linked individually at the record level; that is, when one of the items sharing the relationship is displayed, the link to the other record might be highlighted, and users might go back and forth between these items. These links could appear at the record level only, and not at the summary display level.

\section{MOVIng TOWARd NeW SCHEMES FOR DISPLAY}

Although it is not within the scope of this paper to outline how a new display scheme could be implemented, it will be briefly addressed here. It is well within the capacity of current computer technology to create displays that identify clearly various classes of materials. Such displays could be designed using various approaches, for example, using graphical, hierarchical tree-structures to illustrate the types of materials retrieved in a search. The computer could also create permanent links among records so that every record would always be linked to the entire set of records related to it. An advantage of the electronic environment is that it can provide relationship-based displays without the hazards such displays presented in the card environment; that is, users would always be able to see a summary screen that identifies clearly the classes of related items retrieved.

Although it is within the power of the computer to create relationship-based displays, two major obstacles must be overcome first: the inadequate identification of relationships in existing cataloging records and the limitations of current cataloging practice and the MARC format. To eliminate the first obstacle it would be necessary to identify existing cataloging records that lack appropriate links and then upgrade them by adding those links. It is likely that upgrading existing records would be prohibitively expensive. A compromise would be to upgrade cataloging for only those records associated with works and authors represented by large numbers of records and sought frequently by catalog users. This worst-case approach, while far from ideal, would lower the cost of upgrading current records by limiting its application to those works and authors that are both sought frequently by catalog users and are most likely to result in long, disorganized displays.

Eliminating the second obstacle, the limitations of cataloging practice and the MARC format, is more of a challenge. As noted several times in this paper, AACR2R does not identify relationships between items consistently. AACR2R, like many of the cataloging codes that preceded it, restricts itself to the creation of individual cataloging records and says little about catalog display. While rules for record construction might have been suf- 
ficient to guarantee fulfillment of the second objective in the card environment, they are not sufficient to guarantee it in the online environment. Ronald Hagler has put it this way $(1989,212)$ :

AACR2 is still written as if it were a code only for inputting data. Use of the computer, however, separates what is input from its output, or display, formats, allowing selection and reformatting decisions to intervene. Output formats have unfortunately gone somewhat adrift of the code and seem to be considered by many to be independent of cataloging rules. Special attention is now required to reintegrate them with those rules, especially in the context of online catalogues.

Widespread implementation of relationship-based displays would require an expansion of the scope of the cataloging rules. Although AACR2R purports to endorse the Paris Principles, which include the statement of the objectives of the cata$\log$, it does not explicitly provide for the second objective in catalog displays. If the objectives are to be truly accepted and endorsed, then at some level AACR2R must provide standards or guidelines that implement them.

The number of suggestions for substantial changes in the MARC format is increasing. MARC has many problems (see, for example Leazer 1992), not the least of which is its limited ability to show relationships. Heaney (1995) presents a plan to restructure MARC records that could be used to create the type of displays presented here.

\section{Conclusion}

In an ideal online catalog, users would have the ability to custom-design their own displays to meet their own specific information needs. Relationship-based displays meet the needs of those users interested in seeing the range of materials available in a given library on a given work or author and would assist other users in the selection of a particular item or items. They also have the potential of significantly shortening and simplifying long displays. As Buckland, Norgard, and Plaunt (1993) noted, it is now relatively easy for our catalogs to provide a variety of record arrangements; for example, arrangements by publication date or by other elements of a cataloging record. It is not so easy, however, for existing catalogs to provide organized, relationship-based displays, nor would it be easy for users to articulate a need for a relationship-based display. It is only members of the cataloging profession who, understanding and endorsing the objectives of the catalog, have the power to change the current situation such that fulfillment of the second objective becomes a reality. Such a change is long overdue.

\section{Works Cited}

American Library Association. 1942. ALA rules for filing catalog cards. Chicago: American Library Association.

. 1949. A.L.A. cataloging rules for author and title entries. $2 \mathrm{~d}$ ed. Chicago: American Library Association. 1968. A.L.A. rules for filing catalog cards. 2d. ed. Chicago: American Library Association.

1980. ALA filing rules. Chicago: American Library Association.

Anderson, James D. 1982. Catalog file display: Principles and the new filing rules. Cataloging \& classification quarterly 1 , no. 4: 3-23.

Anglo-American cataloguing rules: North American text. 1967. Chicago: American Library Association.

Anglo-American cataloguing rules. 1978. 2d ed. Ottawa: Canadian Library Association.

Anglo-American cataloguing rules. 1988. 2d ed., 1988 rev. Ottawa: Canadian Library Association.

Ayres, F. H., L. P. S. Nielsen, M. J. Ridley, and I. S. Torsun. 1995. The Bradford OPAC: A new concept in bibliographic control. West Yorkshire: British Library Research and Development Department.

Bernhardt, Melissa M. 1988. Dealing with serial title changes: Some theoretical and practical considerations. Cataloging \& classification quarterly 9, no. 2: 25-39.

Boston Athenæum. 1874-1880. Catalogue of the Library of the Boston Athenæum, 1807-1871. Boston: Boston Athenæum.

Buckland, Michael K., Barbara A. Norgard, and Christian Plaunt. 1993. Filing, filtering, and the first few found. Information technology and libraries 12: 311-19.

Carlyle, Allyson. 1996. Ordering author and 
work records: An evaluation of collocation in online catalog displays. Journal of the American Society for Information Science 47: 538-54.

Cutter, Charles A. 1904. Rules for a dictionary catalog. 4th ed., rewritten. Washington, D.C.: Govt. Print. Off.

Domanovszky, A. 1975. Functions and objects of author and title cataloguing: A contribution to cataloguing theory. Munich: Verlag Dokumentation.

Hagler, Ronald. 1989. The consequences of integration. In The conceptual foundations of descriptive cataloging, ed. Elaine Svenonius, 197-218. San Diego: Academic Pr.

Heaney, Michael. 1995. Object-oriented cataloging. Information technology and librar. ies 14 , no. 3: $135-53$.

Helmer, John. 1987. Cataloging, economics, and the experience of works. Master's thesis, University of California, Los Angeles.

Hines, Theodore C. 1963. Machine arrangement of alphanumeric concordance, thesaurus, and index entries: The need for compatible standard rules. In American Documentation Institute, 26 th Annual Meeting, Chicago, Ill., October 1963, 7-8. Washington, D.C.: American Documentation Institute.

International Federation of Library Associations. 1971. Statement of principles adopted at the International Conference on Cataloguing Principles, Paris, October, 1961. Annotated edition with commentaries and examples by Eva Verona. London: IFLA Committee on Cataloguing.

Jackson, Sidney L. 1958. Catalog use study. Chicago: American Library Association.

Jewett, Charles C. 1853. Smithsonian report on the construction of catalogues of libraries, and their publication by means of separate, stereotyped titles, with rules and examples. $2 \mathrm{~d}$ ed. Washington, D.C.: Smithsonian Institution.

Leazer, Gregory H. 1992. An examination of data elements for bibliographic description: Toward a conceptual schema for the USMARC formats. Library resources \& technical services 36: 189-208.

Leazer, Gregory H., and Richard P. Smiraglia. 1996. Toward the bibliographic control of works: Derivative bibliographic relationships in an online union catalog. In Digital Libraries 1996: Proceedings of the first ACM International Conference on Digital Libraries, Bethesda Md., USA, ed. Edward A. Fox and Gary Marchionini, 36-43. New York: Association for Computing Machinery.
Library of Congress. 1956. Filing rules for the dictionary catalogs of the Library of Congress. Washington, D.C.: Processing Department.

_ 1980. Library of Congress filing rules. Prepared by John C. Rather and Susan C. Biebel. Washington, D.C.: Library of Congress.

Lubetzky, Seymour. 1953. Cataloging rules and principles: A critique of the A.L.A. rules for entry and a proposed design for their revision. Washington, D.C.: Processing Department, Library of Congress.

- 1960. Code of cataloging rules: Author and title entries. An unfinished draft. American Library Association.

- 1963. The function of the main entry in the alphabetical catalogue-One approach. Working paper no. 2. In International Federation of Library Associations. International Conference on Cataloguing Principles, Paris, 9-18th October, 1961. Report, 139-43. London: Clive Bingley.

1969. Principles of cataloging. Final report. Phase I: Descriptive cataloging. Los Angeles, Calif.: Institute of Library Research, University of California.

O'Neill, Edward T., and Diane Vizine-Goetz. 1989. Bibliographic relationships: Implications for the function of the catalog. In The conceptual foundations of descriptive cataloging, ed. Elaine Svenonius, 167-79. San Diego: Academic Pr.

Online catalog screen displays: A series of discussions. Report of a conference sponsored by the Council on Library Resources at the Lakeway Conference Center, Austin, Texas, March 10-13, 1985. 1986. Washington, D.C.: Council on Library Resources.

Panizzi, Antonio. 1841. Catalogue of printed books in the British Museum. Vol. 1. London: Printed by order of the Trustees.

Pettee, Julia. 1936. The development of authorship entry and the formulation of authorship rules as found in the AngloAmerican code. Library quarterly 6: 27090 .

Scheerer, George. 1959. Card catalog arrangement. Library resources \& technical services 3: 140-45.

Smiraglia, Richard Paul. 1992. Authority control and the extent of derivative bibliographic relationships. Ph.D. diss., Univ. of Chicago.

Svenonius, Elaine. 1988. Clustering equivalent bibliographic records. In Annual review of OCLC research, July 1987-June 1988, 6-8. Dublin, Ohio: OCLC. 
1991b. A summary of the treatment of bibliographic relationships in cataloging rules. Library resources \& technical services 35: 393-405.

Vellucci, Sherry L. 1990. Uniform titles as linking devices. Cataloging \& classification quarterly 12, no. 1: 35-62.

Wellisch, Hans $H .1983$. The ALA filing rules: Flowcharts illustrating their application, with a critique and suggestions for improvement. Journal of the American Society for Information Science 34: 313-30.

Wiberley, Stephen E., Robert Allen Daugherty, and James A. Danowski. 1995. User persistence in displaying online catalog postings: LUIS. Library resources \& technical services 39: 247-64.

Wilson, Patrick. 1983. The catalog as access mechanism: background and concepts. $\mathrm{Li}$ brary resources \& technical services 27: 4-17. 1989a. Interpreting the second objective of the catalog. Library quarterly 59: 339-53.

1989b. The second objective, In
The conceptual foundations of descriptive cataloging, ed. Elaine Svenonius, 5-16. San Diego: Academic Pr.

Yee, Martha M, 1994a. Manifestations and near-equivalents of moving image works: Theory, with special attention to movingimage materials. Library resources \& technical services 38: 227-55.

1994b. What is a work? Part 1: The user and the objects of the catalog. Cataloging \& classification quarterly 19 , no. 1 : $9-28$.

1994c. What is a work? Part 2: The Anglo-American cataloging codes. Cataloging \& classification quarterly 19 , no. 2 : $5-22$.

1995a. What is a work? Part 3: The Anglo-American cataloging codes. Cataloging \& classification quarterly 20 , no. 1 : 25-46.

1995b. What is a work? Part 4: Cataloging theorists and a definition abstract. Cataloging \& classification quarterly 20, no. 2: 3-24. 